\title{
From American Acts to CPTPP Rules: the Enlightenment to Patent Linkage Reforms in China*
}

\author{
Shun Diao \\ Law School \\ Beijing Normal University \\ Beijing, China 100875
}

\begin{abstract}
The patent linkage rules in CPTPP belong to the TRIPS-plus clause, which are divided into two types, including soft ones and strong ones. The member states of CPTPP can choose either of the two. Different from the soft ones, strong patent linkage rules pay more attention to the expansion of the patent rights of the brand name manufacturer, rather than the resolution of disputes. Though not as the member state of CPTPP, China would further establish the patent linkage system. Learning from the experience of U.S., Canada, Australia and Singapore, the system of patent linkage should be based on the HWA. It is wise to regulate the patent linkage system under the Chinese patent law and under the law of pharmaceutical administration. The coordination and cooperation between CFDA and SIPO should also be strengthened. In addition, it's essential for China to establish the disclosure of patent information system like Orange Book and provide some provisions related to the disciplinary mechanisms on the notification obligations. Furthermore, referring to foreign legal system, a set of controls is also needed for the reduction or prevention of the lawsuit abuse.
\end{abstract}

Keywords-CPTPP; patent linkage system; generic drug; brand name drug

\section{INTRODUCTION}

After Donald Trump signed an executive order to officially withdraw U.S. from Trans-Pacific Partnership Agreement (hereinafter "TPP”), 11 countries [1]led by Japan renamed TPP as Comprehensive Progressive Trans-Pacific Partnership (hereinafter "CPTPP") and officially signed it in Santiago, capital of Chile, on March 8. The full-text version of the CPTPP was published on the official website of the New Zealand Ministry of Foreign Affairs and Trade on February 21, 2018.[2]Among the provisions of CPTPP, intellectual property rights represented by pharmaceutical patents have always been issues of great controversy since the TPP negotiations. In CPTPP, several patent clauses[3]are suspended, but the patent linkage clause is retained in CPTPP. The patent linkage system also has the attribute of TRIPS-plus compared to the patent provisions suspended, the reason of which is a question worth considering. In addition, at the end of 2017, China successively announced

*Phased achievements of research project sponsored by Sichuan IPR Education Training Base (Southwest Jiaotong University) in 2015 "The Conflict and Coordination between TPP and China's intellectual property law" (IP011507).
"Opinions on Deepening the Reform of the Review and Approval System and Encouraging the Innovation of Pharmaceutical and Medical Devices" (hereinafter "Opinions") and "Measures for the Administration of Drug Registration (Revised Draft)" (hereinafter "Revised Draft"). These documents released the signal that the patent linkage system would be thoroughly established in China. Due to the fact that China had less formal patent linkage in the past and lacked experience, this paper intends to explore the origin of the patent linkage system, analyze the reason why it is extended to countries outside the United States. Furthermore, the experience of the patent linkage system in the United States and CPTPP countries will be referred with the aim of constructing patent linkage system in China.

\section{CPTPP AND PATENT LINKAGE CLAUSES}

Patent linkage refers to a practice by some national regulatory authorities of denying approval of generic drugs that are linked to an existing patent. [4]Linkage requirements will delay the entry of every single generic product into the market if the originator drug is under patent.[5] In other words, the competent authority would not allow the grant of drug marketing approval to any third party prior to the expiration of the patent term, unless approved to by the patent owner. The patent linkage system is not required by the TRIPS Agreement, but regarded as mandatory requirement by CPTPP. The member states of CPTPP shall reflect the regulation of the patent linkage clauses in their own domestic laws. Obviously, the patent linkage rules of CPTPP have exceeded the minimum protection standard of the TRIPS Agreement and hence viewed as the TRIPS-plus clause. In the meantime, the CPTPP also stipulates that the types of patent linkage rules are not the uniqueness, and member states can choose either of the two rules provided by CPTPP, i.e., soft ones and strong ones.

\section{A. Soft Patent Linkage}

Under Article 18.53(1), the details of soft patent linkage rules provided by CPTPP are as follows:

If a Party permits, as a condition of approving the marketing of a pharmaceutical product, persons, other than the person originally submitting the safety and efficacy information, to rely on evidence or information concerning the safety and efficacy of a product that was previously 
approved, such as evidence of prior marketing approval by the Party or in another territory, that Party shall provide: (a) a system to provide notice to a patent holder or to allow for a patent holder to be notified prior to the marketing of such a pharmaceutical product, that such other person is seeking to market that product during the term of an applicable patent claiming the approved product or its approved method of use; (b) adequate time and opportunity for such a patent holder to seek, prior to the marketing of an allegedly infringing product, available remedies in subparagraph (c); and (c) procedures, such as judicial or administrative proceedings, and expeditious remedies, such as preliminary injunctions or equivalent effective provisional measures, for the timely resolution of disputes concerning the validity or infringement of an applicable patent claiming an approved pharmaceutical product or its approved method of use. [6]

It can be seen from the above statement that soft patent linkage rules contain the following vital elements: (1) the publicity of the patent information on the brand name drug; (2) the notification obligation of the generic drug manufacturers; (3) relief approach of the patent holder. If the generic drug manufacturer does not on the basis of any safety and efficacy information supplied by previously approved brand name drug, or if the applicant relies on the information of unapproved drugs, the patent linkage is not applied. By contrast, if the generic drug is on the basis of any safety and efficacy information submitted by previously approved brand name drug manufacturers, the generic drug factory shall notify the patent holder so that the patent holder has enough time to seek remedial measures before the marketing of allegedly infringing generic drug. In this process, the examination of generic drugs and the settlement of patent disputes are separated and the issue of patent infringement could be still applied to justice. From the aspect of language expression, the soft patent linkage rules pay more attention to the settlement of disputes rather than the expansion of the effectiveness of the brand name drug. The soft patent linkage system in CPTPP is similar to the related clauses in U.S.Australian FTA, which are relatively flexible with small pressure on law enforcement from the authorities.

\section{B. Strong Patent Linkage System}

If the CPTPP member states fail to provide the soft patent linkage rules in their domestic law, the strong patent linkage rules shall be stipulated. As an alternative to soft patent linkage rules, Under Article 18.53(1), CPTPP states that a Party shall instead adopt or maintain a system other than judicial proceedings that precludes, based upon patent-related information submitted to the marketing approval authority by a patent holder or the applicant for marketing approval, or based on direct coordination between the marketing approval authority and the patent office, the issuance of marketing approval to any third person seeking to market a pharmaceutical product subject to a patent claiming that product, unless by consent or acquiescence of the patent holder.[7]

In other words, if the contracting party does not specify a soft patent linkage rule, a strong patent linkage rule is needed. Under this rule, the consent or acquiescence of the patent holder determines whether the generic drug could obtain market approval nor not. To some extent, the competent authority shall not allow the generic drug to enter the market until the expiration of the patent for the brand name drugs, unless it obtains the consent or acquiescence of the patent holder. Similar to the United States-Chile Free Trade Agreement, the strong patent linkage system imposes so much enforcement obligation on the competent authority. And it requires the well coordination between the patent office and the drug marketing approval authorities. Moreover, it automatically prohibits the regulatory approval of generic drugs, and does not require patent holders to seek private remedy to impede the marketing approval of suspected infringing generic drugs. Among the strong patent linkage rules, more attention is paid to the expansion of the patent rights for the brand name manufacturer, rather than the resolution of disputes. This is the biggest difference of these two patent linkage rules.

\section{Summary and Comment}

Initially, the patent linkage system was exclusive in the U.S. years ago. Later it was inherited by Canada, Australia, Singapore and other countries through bilateral agreements. Eventually, it's accepted by multilateral agreements such as CPTPP. Reasonably well-designed patent linkage system helps to provide a simplified marketing approval process for generic drugs, and shorten the drug approval process, reduce the price of generic drugs. Moreover, it provides a way for pharmaceutical patent holders to safeguard their rights as early as possible before the generic drugs enter the market, thus realizing the interests balance between generic drugs, brand name drugs and the public. However, in the practical operations, this system has been taken advantage by the patent holder for malicious lawsuit, delaying the availability of generic drugs. What are worse, unrelated patents of brand name drugs may hinder the marking approval of generic drugs. To some extent, it gives an exclusive right to grant patent holders more than a statutory period of 20 years. Even if penalties clauses have been provided by some countries regarding the abuse of the patent linkage system, the benefits of this system in preventing the generic pharmaceutical factory from entering the relevant market are more than the punishment. Therefore, the abuse of the system is not effectively regulated. Though the system was originally used to balance the interests of between generic drugs, and brand name drug manufacturers, a slight carelessness in the design of the legal system may cause the benefits to tilt toward the brand name drug manufacturers. This in turn hinders the marketing approval of generic drugs and becomes detrimental to the health and safety of the public. As a result, it arouses the criticism of the public for the shortcomings and gets opposed by countries or regions represented by India [8] and the EU [9].

\section{The Evolution of PATENT LinKAGE Systems}

The patent linkage system originated in the HatchWaxman Act (hereinafter "HWA"). Nowadays, the U.S., Canada, Australia, Singapore and some other countries have provided patent linkage provisions in their domestic laws. In 
this chapter, how the patent linkage system has evolved from one country to several countries will be analyzed, which is helpful for China to understand the nature of the patent linkage system when transplanting this system.

\section{A. Origin: Hatch-Waxman Act of 1984}

Before the U.S. established the patent linkage system, Federal Food, Drug, and Cosmetic Act (As amended through 1962)[10] regulated that the FDA with evidence of safety and effectiveness of drugs should be provided for both the brand name drugs and the generic drugs before obtaining marketing approval. In this act, same as the brand name drugs, the generic drugs were also required to test for safety and effectiveness. This increased the cost of generic drugs which were eventually transferred to consumers. In addition, before the establishment of the patent linkage system, the market approval of generic drugs and patents of brand name drugs were basically disconnected. In other words, FDA had no idea whether the generic drugs infringed others patents nor not. This was not conducive to the protection of patent holders. Based on the balance between two potentially competing policy interests-inducing pioneering development of pharmaceutical formulations and methods, to facilitate the efficient transition to a market with low-cost, generic copies of those pioneering inventions at the close of a patent term, the patent linkage system was set up by HWA. The system mainly includes the following supporting measures:

1) Pharmaceutical-related patents listed in the orange book: The patent linkage system of the Orange Book can be said to be the essence of the HWA. HWA allow a drug manufacturer to rely on the clinical studies performed by the New Drug Applicant and to forego the safety and effectiveness testing of its new generic drug, the streamlined process named Abbreviated New Drug Application(ANDA).Once a NDA is approved by FDA,FDA would publish a listing of the drug together with the patent information pertaining to the drug in a publication called Approved Drug Products with Therapeutic Equivalence Evaluations(commonly referred to as the "Orange Book").The importance of Orange Book listings are reflected in the following aspects:(1)ANDA applicants are required to make certifications with respect to patents listed in the Orange Book;(2)the NDA holder can use the listed patents to invoke a temporary stay against approval of any ANDAs.[11]

2) Notification requirement: When the marking approval of generic drugs is applied, the ADNA applicant shall select one of the four following certifications, such as:(I) no patent related to the pioneer drug has been filed; (II) the relevant patent has expired; (III) the patent is set to expire on a certain date; or paragraph IV) the patent is invalid or will not be infringed by the manufacture, use, or sale of the generic drug for which the ANDA is submitted.[12]

Among them, Paragraph I, II and III certification would not pose a challenge to the brand name drug. For the Paragraph I or Paragraph II, the approval could be obtained directly by FDA, and generic drug manufacturers will not be hindered by the brand name drug. As for Paragraph III filings, FDA is required to allow the marketing approval of generic drugs after the expiration of the competing brand name patents. Therefore, the conflicts between generic drugs and brand name drugs based on the first three Paragraph certifications are not obvious. If the generic drug manufacturer submits a Paragraph IV certification, the patentee of the brand name drug shall be notified by the generic drugs within 20 days of submitting the application, and the facts and legal basis of invalidity or noninfringement of the listed patents in Orange Book need to be explained. If the generic drug successfully challenges invalid patents of brand name drugs under Paragraph IV, the generic drugs could enter the market earlier before the expiration of brand name drugs, and enjoy the profits originally belonged to brand name drugs, thus gaining considerable market interests.

The notification obligations of generic drug manufacturers help the patent holder to eliminate the cost of search for patent infringement and learn the tactical progress of competitors earlier. The generic drugs must actively inform the brand name drugs of application status, exposing themselves to the risk of being sued and even leaking their business strategy.

3) 30-Month Stays on ANDA Approval: When the generic drugs challenge the invalid patents of brand name drugs successfully under Paragraph IV, the generic drug could enter the market before the expiration of brand name drugs. Therefore, if the patent holder of the brand name drug does not file a patent infringement action within 45 days after receiving the notification, FDA would continue the review of generic drugs. [13] Once the FDA has passed the application of a generic drug, the profitability of the brand name drugs would be affected due to the price advantage of generic drugs. Thus, under Paragraph IV, the generic drugs are vulnerable to the claim of brand name drug manufacturer for infringement. By contrast, if the patent holder files an infringement action within the time limit, the review of the generic drugs by FDA will be suspended until the court makes a decision. This stay period is limited to a maximum of 30 months. After the deadline of the stay, the patent holder has right to request the court to issue a temporary injunction in the lawsuit. In this case, the temporary injunction and the stay period do not conflict with each other.

4) A First-to-File ANDA eligible for 180-Day exclusivity: The first-to-file ANDA is designed to encourage generic drugs to challenge the validity of brand name drugs' patents. On the one hand, it aims to bring cheap, safe and effective generic drugs to the market and benefit the public. On the other hand, due to the exclusive effect of patents, the patentee of the drug is enabled to obtain exclusive rights for a certain period. In fact, drugs with invalid patents would consume social costs if not challenged by any generic drug manufacturer. The scientific literature has proved that brand 
name drug manufacturers are extending their periods of exclusivity rights on certain compounds using secondary patents and secondary patents are invalidated at a much higher rate than active ingredient patents in Hatch-Waxman litigation. Therefore, in accordance with HWA, the first filing under Paragraph IV was filed which successfully challenged the invalid patents, 180 days of market exclusive sales will be enjoyed as an incentive to encourage generic drugs to challenge the validity of patents.[14] In other words, within this 180-day period, the second generic drug will not be approved by FDA. The 180-day period of exclusivity allows pharmaceutical consumers to rely on the inherent effects of this generic drug during this exclusive period. However people doubt whether there is attractiveness for generic drugs during the 180 days of exclusive sales. In most cases, it is almost impossible for generic drugs to enter the pharmaceutical market within 180 days.

\section{B. Amendment: Medicare Modernization Act of 2003}

With the implementation of the HWA, the generic pharmaceutical industry of U.S. has indeed achieved a great development. The use of generic drugs in the total prescription drugs increased from $19 \%$ in 1984 to $89 \%$ in 2015. [15]Meanwhile, in the judicial practice, such as the improper patents listed in the Orange Book, brand name drug manufacturers start such procedures frequently to suspend the review of the generic drug, leading to the generics drug factories passive in litigation and unfair competition in the reverse settlement agreement. To solve these problems, the U.S. Congress released the Medicare Prescription Drug, Improvement and Modernization Act of 2003((hereinafter "MMA") [16], in which a series of adjustments were made regarding to the shortcomings in the implementation of the HWA.

De-listing of patents improperly listed in orange book: Due to the fact that brand name drug manufacturers frequently listed non-essential patents in the Orange Book, such as metabolite patents, intermediate product patents, method patents, the type of patents listed in the Orange Book was limited after the amendments. [17]As a result, to a certain extent, it prevented the patent holders from improperly publishing irrelevant patents, in turn reducing the occurrence of evergreen patents.

Prohibiting more than a single 30-month stay: After the enactment of HWA, some brand name drug manufacturers used repeated 30 month stays to keep a generic product off the shelves by listing additional patents to the FDA's "Orange Book" after an applicant filed an ANDA. The act of MMA is to improve the abuse of stay, limit the duration of a stay of up to 30 month [18], thus preventing patented pharmaceutical companies from initiating multiple stays and delaying the marketing of generic drugs.

1) Ameliorating the patent litigation: When the ANDA applicant submits a Paragraph IV certification and notifies the brand name drug manufacturer, if the brand name drug manufacturer does not file a patent infringement suit within 45 days of receiving notice, then the generic drug manufacturer could file declaratory judgment actions to confirm that its generic drug does not infringe on patents of brand name drugs. [19]This reduces the risk of being sued by the brand name drug manufacturer after the generic drug enters the market.

Besides this, an ANDA applicant may assert a counterclaim seeking an order requiring the NDA holder "to correct or delete" patents information in the Orange Book, on the grounds that the patent does not claim the drug for which it was approved or an approved method of using the drug.[20]

2) Amending the 180-Day Exclusivity Provisions: The brand name drug manufacturer and the generic drug manufacturer sign the reverse agreement, and the former would pay a counteroffer to the latter in return for the commitment of the generic drug manufacturer to not let the generic drugs enter the market for a certain period of time. Such behaviors result in unfair competition. To mitigate the unfair competition caused by the reverse settlement agreement, the MMA Act requires all agreements related to patents of generic drugs including patent litigation settlement agreements should submit a report to the competent authority such as FTC and DOJ within 10 days after the signing of the agreement. Anyone who violates the reporting obligations would face fines of up to $\$ 11,000$ per day up to the date of their submission. [21]Related agreements are involved in restricting competition will be investigated by FTC and DOJ, without disclosing the contents of the agreement by the competent authority.

\section{Spread: from U.S. to Multiple Countries}

The patent linkage system originated from the U.S. A number of countries including Canada, Australia, Chile, Singapore, Jordan, Morocco, Bahrain, Oman, Colombia, Per, Honduras, Guatemala, Nicaragua, Costa Rica, Dominican Republic, Peru, South Korea and so on have signed bilateral agreements with U.S. included patent linkage clauses. Among these countries, some are CPTPP countries, such as Canada, Australia and Singapore.

1) Canada: The U.S. exerted pressure on Canada through the North American Free Trade Agreement (hereinafter "NAFTA"), and prompted Canada to formally adopt the Patented Medicines(Notice of Compliance) Regulations (hereinafter "NOC Regulations")in 1993. Canada is the first country outside the United States to establish a patent linkage system in a similar way to the U.S.:(1) For the first applicant for a brand name drug, patent information related to the drugs shall be provided; (2) Generic drugs are not allowed to get the approval within the validity period of the brand name drugs' patent; (3) Generic drugs without infringing others' patent rights are allowed to enter the market earlier; (4) For generic drugs with disputes over patent infringement, there is a special settlement mechanism before entering the market.[22]

Unlike the patent linkage system of U.S., the legal authority of NOC Regulations is based on Article 55.2(4) of the Patent Law, not providing the patent linkage system 
under the drug administration law system. Meanwhile, Canada's legislation does not have exclusivity provisions for generic drugs that challenge the invalid patents of brand name drugs.

2) Australia: In 2005, the US-Australia Free Trade Agreement was officially implemented, and the patent linkage system was successfully applied in Australia. Learning from the experience in U.S, great efforts have been made to minimize the adverse effects of patent linkage. For instance, specific provisions are developed against evergreening; meanwhile, drug patents are based strictly on the proved therapeutic importance of the drug. Australia has restricted patent linkage provisions for over generic drugs in contrast to U.S. There are provisions against ever-greening and also a patent linkage provision under Section 26(B) of Therapeutic Goods Administration Act, 1989.[23]The most striking feature of the Australian patent linkage provision is its heavy penalty that is imposed for false and misleading information.

3) Singapore: The US-Singapore Free Trade Agreement was reached on January 1, 2004 which involved the patent linkage system. The system also modeled on the HWA of U.S. For example, the brand name drugs have the right to decide whether or not to prosecute the generic drugs within the 45 day after receiving the notification. If the lawsuit is filed within 45 days, the 30-month stay will start automatically. Otherwise, the competent authority will continue to review the marketing approval of generic drugs.[24]However, unlike the U.S., the exclusive sales period of certain generic drugs is not provided.

\section{ENLIGHTENMENT TO PATENT LINKAGE REFORMS IN CHINA}

China's pharmaceutical industry is dominated by generic drugs with asymmetrical disadvantages in the disclosure of medical patent information. It lacks cross-domain patent talents in pharmaceutical industry. The ANDA process for the generic drug applicant could refer to the test data of the drug application at the time of approval by competent authority, and the evidence for the availability and bioequivalence of generic drugs is required for generic drugs. Compared to relatively long and complicated clinical trial procedures of brand name drugs, it lowers the costs for generic drug manufacturers and to a certain extent, reduces the market price of generic drugs. Due to the destructive effect of generic drugs on the market price of the brand name drug, the profitability of the brand name drugs manufacturers will be affected. This leads the brand name drug factories to take various legal laws to delay the time that generic drugs enter into the market. Therefore, it is particularly important to design a well-developed patent linkage system for the benefit balance between brand name drugs and generic drugs in China.

\section{A. Paradoxical Chinese Patent Linkage System}

The Measures for the Administration of Pharmaceutical Registration (for Trial Implementation) promulgated on
October 30, 2002 is the first time that China has made regulations on patent issues in drug's registration and approval. Nevertheless, it is still far from patent linkage system in its true sense. For instance, there are no provisions to request the pharmaceutical-related patents listed in the patent information system like Orange Book and few articles about notification requirement to generic drug manufacturers, not to mention 30-Month Stays on ANDA Approval or a first-to-file ANDA eligible for 180-Day Exclusivity. China only requires generic drugs to explain the status of patent ownership or declare that it does not infringe the patents of brand name drugs in a publicized manner.

\section{B. The General Idea of Constructing Patent Linkage Systems in China}

Currently, China's pharmaceutical industry is dominated by generic drugs and depends on the supply of foreign brand name drugs. The independent research and development capabilities of Chinese medicines are still in the status of infancy. Against this background, it is necessary to control the price of drugs at a certain level and prevent the patent linkage system from being abused by the brand name companies. That is to say, the soft patent linkage is more suitable to China than the strong ones

In addition, besides the patent linkage system should under the law of pharmaceutical administration, it also shall be distributed into Chinese patent law too. Though both patent linkage system and bolar exception rules are stipulated in the HWA, it is a pity that only the latter is accepted by current Chinese Patent Law. Chinese patent law stipulates that any person producing, using, or importing patented drugs or patented medical apparatus and instruments is required to provide information for administrative examination and approval, and shall not infringe patent right of other people. [25]The article is recognized as Bolar exception. However, it's hard to determine whether the act of submitting approval application for a generic drug manufacturer before the expiration of the brand name drug is infringement nor not. In fact, U.S. stipulates artificial infringement in the patent linkage system of HWA; while such behavior is not provided in China. In other words, regulating the patent linkage system under the patent law and the pharmaceutical administration law contributes to the reduction of the conflict between the patent linkage system and the Bolar exception rule.

Moreover, linking between drug approval and drug patents could not be separated from the cooperation and coordination between the management department of drug registration approval and the patent management department. Such mechanism between these departments is exactly the essence of the patent linkage system. The experience of U.S. and CPTPP countries show that the two relevant departments are independent and closely cooperated in their work, thus effectively reducing the occurrence of generic patent infringement disputes and reaching an effective equilibrium. Previous experience of countries outside the China proves that coordination and cooperation between CFDA and SIPO should be strengthened, so that each department could take its advantages to provide the others with the necessary 
support. For example, it is suggested that a platform shall be established to share the patent drug information and maximize the prevention of patent infringement lawsuits for generic drugs entering the market.

\section{The Specific Design of Patent Linkage Systems in China}

1) Creating the disclosure of patent information system: As improper registration is the most critical problem in the patent linkage system, the eligibility requirement for patent listing should be constrained. The patent related to the brand name drug manufacturer entitled to request listing shall be restricted in terms of medicinal ingredient, formulation, dosage form, indication; by contrast the salts, ester, enantiomer or solvates are not list in the patent information system.

2) Improving the notification system: In reference to the HWA regarding notification obligations of generic drugs, the experience of Australia is also worth learning. When the content of the notification is misleading or false, a disciplinary mechanism is in need. Moreover, most of the foreign countries do not provide disciplinary mechanisms when generic drugs fail to fulfill their notification obligations, which may affect the operation of the patent linkage system. To prevent this risk, it's necessary for China to develop some provisions related to the disciplinary mechanisms regarding the notification obligations.

3) Regulating the stay of issuance system: The biggest controversy about the stay is whether to institute an automatic stay. In U.S, Canada, Australia and Singapore, once the brand name drug manufacturer sued the generic drug company, the stay would start automatically, during which the review of generic company will be suspended. In this way, the brand name drug manufacturer could enjoy the equivalent of the temporary injunction easily, which is unfair to generic drug company. Conversely, if the period of the stay does not start automatically, a series of problems like caseloads may occur. As a result, a compromise approach is suitable. That is to develop the standard for starting the stay; meanwhile, a certain margin is required to be submitted by the brand name drug manufacturer to guarantee no abuse of the stay in issuance system.

4) Endowing a first-to-file ANDA with an exclusive sales period: Referring to foreign legal system, in order to introduce a clause allowing the generic drug to challenge the validity of the brand name drug patents in exchange for the earlier entry the market, then the country should design a set of controls to reduce or even prevent the abuse of lawsuits. This is also the trade-off approach of the CPTPP countries when introducing the patent linkage system. In spite of some CPTPP countries such as Australia and Singapore do not provide the exclusive sales period of certain generic drugs like HWA, but I think it's essential for China to grand a period of exclusive sales to a generic drug applicant who challenges the invalid patents of brand name drugs, thus balancing the interests between the generic drug companies and brand name drug companies.

\section{CONCLUSION}

Since the patent linkage system was developed in 1984, it has been adopted by a number of countries outside the U.S. CPTPP suspends several intellectual property clauses, except the patent linkage clause. Though China is not the member state of CPTPP, it plans to establish the patent linkage system. Due to the fact that China's past patent linkage was mere formality and lacked experience, referring to the experience of foreign countries for the construction of China's patent linkage system is reasonable. The patent linkage system should be under the Chinese patent law and the law of pharmaceutical administration; and coordination and cooperation between CFDA and SIPO should be strengthened as well. In addition, there is a need to create the disclosure of patent information system like Orange Book and provide some provisions relating to the disciplinary mechanisms regarding the notification obligations. Referring to foreign legal system, a set of controls is required so as to reduce or even prevent the abuse of lawsuits.

\section{REFERENCES}

[1] The CPTPP is a new free trade agreement between Australia, Brunei, Canada, Chile, Japan, Malaysia, Mexico, New Zealand, Peru, Singapore and Vietnam.

[2] See CPTPP Text Zipped ,https://www.mfat.govt.nz/search/SearchForm?Search=CPTP P\&searchlocale=en_NZ,accessed May 19,2018.

[3] CPTPP suspends several patent clauses related to inventions that are derived from plants,patent term adjustment for unreasonable granting authority delays/curtailment,protection of undisclosed test or other data and protection of new biologics.

[4] See Cynthia Ho,Access to medicine in the global economy:International agreement on patent and related rights,Oxford University Press,2011,p273,quoted in Fighting poison with poison? The Chinese experience with pharmaceutical patent linkage, $11 \mathrm{~J}$. Marshall Rev. Intell. Prop. L. 623,625 (2012).

[5] See Robert Galantucci,Data protection in a US-Malaysia free trade agreement:New barriers to market access for generic drug manufactures,Fordham Intellectual Property,17Media and Entertainment Law Journal,1085,1115(2007).

[6] See CPTPP,art.18.53(1).

[7] See CPTPP,art.18.53(2).

[8] Such linkage would undermine the "Bolar/Early Working" of the patent and deny space for generic medicines,available at http://www.indiankanoon.org/doc/1123372/.

[9] The European Union does not support patent linkage on the grounds that it is contrary to EU regulatory law as it undermines the Bolar Provision,available at https://www.drugpatentwatch.com/blog/patentlinkage-resolving-infringement/.

[10] See Pub. L. No.87-781,76 Stat.780(1962).

[11] See Jacob S. Wharton, Orange Book Listing of Patents under the Hatch-Waxman Act, 47 St. Louis U. L.J. 1027,1031 (2003).

[12] See 21 U.S.C $\$ 355(j)(2)(A)(v i i)$.

[13] See 21 U.S.C $\$ 355(j)(5)(B)(i i i)$.

[14] See 21 U.S.C. $\$ 355(j)(5)(B)(i v)$.

[15] See Nora $\mathrm{Xu}$, AIA proceedings: A prescription for accelerating the availability of generic drugs, 66 Emory L.J. 1007,1012 (2017).

[16] See Pub. L.No.108-173,117 Stat.2066(2003). 
[17] See 21 C.F.R. $\$ 314.53(b)(1)$.

[18] See 21 U.S.C. $\$ 355(j)(5)(B)(i i i)$.

[19] See 21 U.S.C. $\$ 355(j)(5)(C)(i)$.

[20] See 21 U.S.C. $\$ 355(j)(5)(C)($ ii).

[21] See Medicare Modernization Act,Pub.L.No.108-173,§1115(a),117 Stat.2066,2463(2003)

[22] See Ron A. Bouchard, I'm still your baby: Canada's continuing support of U.S. linkage regulations for pharmaceuticals, 15 Marq. Intell. Prop. L. Rev. 71,87 (2011).

[23] See Thomas A Faunce and Joel Lexchin,'Linkage' pharmaceutical evergreening in Canada and Australia, available at http://www.anzhealthpolicy.com/content/4/1/8.

[24] See Patent Linkage in ASEAN countries Compared to the US,available at https://www.mirandah.com/pressroom/item/340patent-linkage-in-asian-countries-compared-to-the-us-2/.

[25] See Chinese Patent Law,art.69.1(5). 